5. Shavit L, Lifschitz M, Slotki I, Oren A, Tauber R, Bitran D, et al. Preoperative renal dysfunction and clinical outcomes of cardiac surgery in octogenarians. Exp Gerontol. 2013;48:364-70.

6. Scandroglio AM, Finco G, Pieri M, Ascari R, Calabrò MG, Taddeo D, et al. Cardiac surgery in 260 octogenarians: a case series. BMC Anesthesiol. 2015; $15: 15$.

7. Arora RC, Manji RA, Singal RK, Hiebert B, Menkis AH. Outcomes of octogenarians discharged from the hospital after prolonged intensive care unit length of stay after cardiac surgery. J Thorac Cardiovasc Surg. 2017; 154: 1668-78.e2.

8. Thakar CV, Worley S, Arrigain S, Yared JP, Paganini EP. Influence of renal dysfunction on mortality after cardiac surgery: modifying effect of preoperative renal function. Kidney Int. 2005;67:1112-9.

9. Koch CG, Li L, Duncan AI, Mihaljevic T, Loop FD, Starr NJ, et al. Transfusion in coronary artery bypass grafting is associated with reduced long-term survival. Ann Thorac Surg. 2006;81:1650-7.
See Article page 1568.

\section{Commentary: Age is just a number?}

Richa Dhawan, MD, MPH, and Mark A. Chaney, MD

The life expectancy in the United States is 78.6 years per Centers for Disease Control and Prevention reports. ${ }^{1}$ It is estimated that by 2050, 19 million Americans will be 85 and older and 1 million will be 100 years and older. ${ }^{2}$ Although an amazing achievement of medical advancement and technology, it is an immense challenge to health care delivery. The majority of these individuals will be living with chronic health conditions requiring medical or surgical care. Often this vulnerable population is excluded from clinical trials, yet the health care community needs vigorous scientific research to understand this group's unique medical needs. In this light, the Journal presents an important study by Atladottir and colleagues. This retrospective study included 2342 patients older than the age of 80 years undergoing open-heart surgery. ${ }^{3}$ The authors performed a logistic regression analysis to determine preoperative, intraoperative, and postoperative risk factors associated with an increase in morbidity and mortality. They found that severe renal impairment (glomerular filtration rate $<40 \mathrm{~mL} / \mathrm{min}$ ) and prolonged cardiopulmonary bypass time (>180 minutes) were associated with greater than $50 \%$ mortality at 1 year. Postoperative intensive care length

\footnotetext{
From the Department of Anesthesia and Critical Care, University of Chicago Medical Center, Chicago, Ill.

Disclosures: Authors have nothing to disclose with regard to commercial support.

Received for publication March 19, 2020; revisions received March 19, 2020; accepted for publication March 20, 2020; available ahead of print April 6, 2020

Address for reprints: Richa Dhawan, MD MPH, Department of Anesthesia and Critical Care, University of Chicago Medical Center, 5841 South Maryland Ave, MC 4028, Chicago, IL 60637 (E-mail: rdhawan@dacc.uchicago.edu).

J Thorac Cardiovasc Surg 2021;162:1579-80

$0022-5223 / \$ 36.00$

Copyright (C) 2020 by The American Association for Thoracic Surgery

https://doi.org/10.1016/j.jtcvs.2020.03.078
}

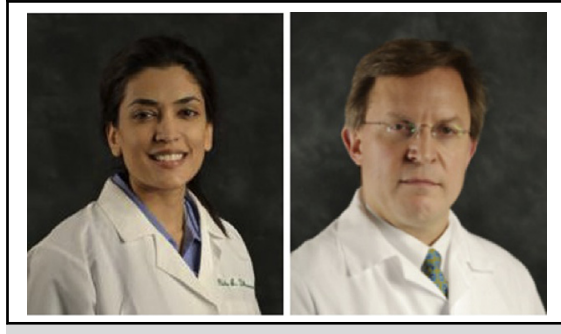

Richa Dhawan, MD, MPH, and Mark A. Chaney, MD

CENTRAL MESSAGE

Octogenarians are a complex patient population. Specific risk factors that predispose them to increased morbidity and mortality after cardiac surgery need to be further elucidated.

of stay greater than 3 days and mechanical ventilation greater than 2 days were also associated with increased mortality within 1 year.

Although the findings of this study are not surprising, they pose vital questions about health care objectives for the very elderly. What is the best care for these patients? Is $50 \%$ mortality acceptable? The study lacks data on postoperative quality of life and cognitive function. Are patients able to return to their normal lives after surgery? As clinicians we lack a comprehensive understanding of the risks and benefits of medical/surgical treatment for the elderly. Part of the puzzle is that chronological age is not necessarily equivalent to biological age. Some octogenarians live independent, active lives, whereas others need assisted living due to a decline in physiological functional capacity. In the last decade, the concept of frailty, rather than age or disease, as immerged as a valuable measure of preoperative risk 
assessment. ${ }^{4}$ The frailty index (a measure of nutrition, level of independent activity, and cognitive capacity) captures the heterogeneity in health status among elderly patients. Patients with a high frailty index have worse outcomes after surgery. The majority of risk factors that increase postoperative morbidity and mortality are non-modifiable (heart failure, dementia); hence, providers cannot mitigate the risk of surgery. However, some risk factors (ie, cardiopulmonary bypass time) as elucidated by Atladottir and colleagues are potentially modifiable. Modifiable variables should be the focus for individualized surgical planning; however, clinicians still need more robust data to fully understand what these are. Given that a subset of elderly patients is at risk of substantial morbidity and mortality without surgical intervention, its essential to make informed shared decisions about recovery, prognosis, and quality of life after surgery. Although the study presented in the Journal is limited, given its retrospective design, the authors should be lauded for their efforts in trying to understand this complex patient population.

\section{References}

1. Centers for Disease Control and Prevention (2019, October 30). National Center for Health Statistics. Available at: https://www.cdc.gov/nchs/hus/contents2018. htm?search=Life_expectancy. Accessed March 15, 2020.

2. National Institute on Aging (2012). Centers of Disease Control and Prevention. Available at: https://www.nia.nih.gov/about/aging-well-21st-century-strategicdirections-research-aging. Accessed March 15, 2020.

3. Atladottir HO, Modrau IS, Jakobsen C-J, Torp-Pedersen CT, Gissel MS, Nielsen DV. Impact of perioperative course during cardiac surgery on outcomes in patients 80 years and older. J Thorac Cardiovasc Surg. 2021;162:1568-77.

4. Clegg A, Young J, Illiffe S, Rikkert MO, Rockwood K. Frailty in elderly people. Lancet. 2013;381:752-62 